\title{
PENERAPAN FUZZY INFERENCE SYSTEM UNTUK MENENTUKAN JUMLAH PEMBELIAN PRODUK BERDASARKAN DATA PERSEDIAAN DAN PENJUALAN
}

\author{
Kecitaan Harefa \\ Teknik Informatika, Universitas Pamulang \\ Email: dosen00842@unpam.ac.id
}

\begin{abstract}
ABSTRAK
Keuntungan yang maksimal diperoleh dari penjualan yang maksimal. Apabila jumlah produk yang disediakan oleh perusahaan kurang dari jumlah permintaan maka perusahaan akan kehilangan peluang untuk mendapatkan keuntungan yang maksimal dan sebaliknya. Oleh karena itu, Perencanaan jumlah pembelian produk untuk persediaan pada PT. Carrefour Puri Indah sangatlah penting. Agar dapat memenuhi permintaan pasar dengan tepat dan dengan jumlah yang sesuai. Faktor-faktor yang perlu diperhatikan dalam menentukan jumlah pembelian, antara lain: jumlah persediaan dan jumlah penjualan. Penelitian ini dilakukan dengan menerapkan metode Fuzzy Inference System dengan menggunakan tiga variabel yaitu jumlah persediaan, jumlah penjualan, dan jumlah pembelian. Hasil dari penerapan metode Fuzzy Inference System terbukti dapat membantu perusahaan dalam membuat keputusan untuk menentukan jumlah pembelian produk agar persediaan sesuai dengan kebutuhan pasar.
\end{abstract}

Kata kunci : Fuzzy Inference System, pembelian produk, persediaan, penjualan.

\section{PENDAHULUAN}

Latar Belakang

Masalah persediaan merupakan

permasalahan yang selalu dihadapi para pengambil

keputusan dalam bidang persediaan. Persediaan dibutuhkan karena pada dasarnya pola permintaan tidak beraturan. Persediaan dilakukan untuk menjamin adanya kepastian bahwa pada saat dibutuhkan produk-produk tersebut tersedia (Sunyoto, 2015).

Masalah dalam persediaan adalah kesulitan dalam menentukan besarnya jumlah persediaan yang harus disediakan dalam memenuhi jumlah permintaan. Carrefour Puri Indah merupakan salah satu perusahaan retail yang sering mengalami masalah dalam persediaan produk. Salah satu masalah yang sering terjadi pada perusahaan ini adalah jumlah persediaan terlalu banyak dan tertumpuk lama. Keadaan ini menyebabkan perusahaan mengeluarkan biaya bunga yang lebih besar. Selain itu, jika barang kosong dapat menyebabkan hilangnya kepercayaan konsumen terhadap perusahaan atau konsumen akan beralih ke produk sejenis dari merek lain. Sebaliknya, apabila persediaan terlalu besar dan tidak sebanding dengan jumlah permintaan, perusahaan akan mengalami kerugian akibat pertambahan biaya bunga uang modal yang tertanam dalam persediaan, pajak, asuransi, biaya penyusutan, penurunan harga, dan kerusakan akibat telah mencapai masa expire (Sunyoto, 2015).
Untuk mengatasi hal ini, maka diperlukan analisa dan pengolahan data historis transaksi penjualan dengan tujuan untuk menentukan tingkat persediaan yang harus tersedia serta kapan pembelian kembali dilakukan untuk menambah persediaan. Hal ini diperlukan untuk menjamin tersedianya persediaan yang tepat dalam kuantitas dan waktu yang tepat.

Pada penelitian ini menggunakan penerapan metode Fuzzy Inference System, dapat digunakan untuk menentukan jumlah dan kapan waktu pembelian produk untuk persediaan. Logika fuzzy dianggap mampu untuk memetakan suatu input kedalam suatu output tanpa mengabaikan faktorfaktor yang ada. Logika fuzzy diyakini sangat fleksibel dan memiliki toleransi terhadap data-data yang ada. Berdasarkan logika fuzzy, akan dihasilkan suatu model dari suatu sistem yang mampu memperkirakan pembelian produk untuk persediaan. Faktor-faktor yang mempengaruhi dalam menentukan pembelian produk untuk persediaan dengan logika fuzzy antara lain persediaan, penjualan, dan pembelian.

\section{Identifikasi Masalah}

Setelah dilakukan analisa pada latar belakang dan kondisi yang terjadi di tempat penelitian, diidentifikasi masalah sebagai berikut:

1. Jumlah persediaan terlalu banyak dan tertumpuk lama sehingga menyebabkan kerugian akibat pertambahan biaya bunga uang modal yang tertanam dalam 
persediaan, pajak, asuransi, biaya penyusutan, penurunan harga, dan kerusakan akibat telah mencapai masa expire.

2. Barang kadang kosong sehingga menyebabkan hilangnya kepercayaan konsumen terhadap perusahaan atau konsumen akan beralih ke produk sejenis dari merek lain.

\section{Tujuan Penelitian}

Tujuan penelitian ini adalah menerapkan metode Fuzzy Inference System, yang dapat membantu suatu perusahaan dalam menentukan pembelian produk untuk persediaan.

\section{LANDASAN TEORI Inventory}

Inventory atau persediaan adalah suatu teknik untuk manajemen material yang berkaitan dengan persediaan (Darmanto, 2012). Manajemen material dalam inventory dilakukan dengan beberapa input yang digunakan yaitu permintaan yang terjadi (demand) dan biaya-biaya yang terkait dengan penyimpanan, serta biaya apabila terjadi kekurangan persediaan (short-age). Pengelolaan persediaan adalah kegiatan dalam memperkirakan jumlah persediaan (bahan baku/penolong) yang tepat, dengan jumlah yang tidak terlalu besar dan tidak pula kurang atau sedikit dibandingkan dengan kebutuhan atau permintaan. Inventory memiliki daur atau siklus yang disajikan pada gambar berikut:

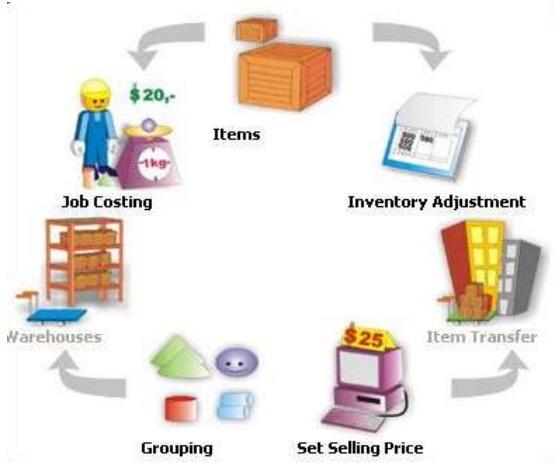

Gambar 2.1 Siklus Inventory (Darmanto, 2012)

\section{Perencanaan Pembelian Barang Dagangan}

Para pelanggan selalu berharap menemukan apa yang mereka cari dari sebuah toko. Selain itu mereka mungkin juga akan membeli barang lain yang tadi tidak rencanakan. Apakah tokoh ritel sudah menyediakan sesuatu yang dicari pembeli? Yang jelas kebutuhan dan keinginan pelanggan sangat beragam, dan toko ritel diharapkan dapat memenuhinya. Untuk dapat memuaskan harapanharapan di atas, fungsi operasional setiap toko ritel harus saling terkoordinasi secara baik. Apakah itu fungsi pembelian barang, pengelolaan gudang, keuangan, operasi toko dan sebagainya.

Perencanaan barang yang baik dapat memberikan keakuratan dalam menentukan apa yang sebaiknya kita beli, bagaimana menyimpannya, kapan barang itu datang, dan kapan membeli lagi atau bagaimana kita harus memajangnya (Sunyoto, 2015).

\section{Menentukan Persediaan Produk}

Ketersediaan produk dapat menentukan presentase permintaan pasar terhadap beberapa SKU yang memuaskan. Semakin tinggi persediaan barang dagangan, semakin besar stok cadangan. Memilih jumlah cadangan yang tepat adalah kunci sukses dalam proses perencanaan keberagaman, karena jika cadangan barang terlalu rendah maka peritel akan kehilangan penjualan dan pelanggan. Jika stok barang terlalu tinggi, ditakutkan sumber daya keuangan dan investasi yang seharusnya dapat digunakan untuk membeli barang lain yang lebih menguntungkan akan terbuang percuma (Sunyoto, 2015).

\section{Strategi Penjualan}

Langkah-langkah penjualan sejak persiapan atau pra penjualan sampai pelaksanaan penjualan dan pemberian layanan purna jual (Puspitasari, 2008) adalah sebagai berikut:

1. Penentuan dan pemantapan tempat usaha.

2. Memobilisasi sumber daya manusia dan dana.

3. Menentukan sitem penjualan.

4. Membuat ramalan penjualan dan menyusun rencana penjualan.

5. Menentukan dan melaksanakan program penjualan, termasuk menentukan daerah penjualan, pemasaran dan cara penjualan.

6. Memelihara persediaan barang dagangan, peralatan dan perlengkapan.

7. Melaksanakan penjualan barang, mulai dari menerima pesanan sampai dengan pembayaran dan pengirimannya, termasuk menerima klaim dan retur.

8. Menyelenggarakan administrasi penjualan.

9. Melaksanakan urusan purna jual (bila ada).

\section{Fuzzy Logic}

Logika Fuzzy adalah suatu cara yang tepat untuk memetakan suatu ruang input ke dalam suatu ruang output (Widodo, 2012). Beberapa contoh 
yang dapat diambil (Sri Kusuma Dewi, 2013) antara lain:

1. Manajer pergudangan mengatakan pada manajer produksi seberapa banyak persediaan barang pada akhir minggu ini, kemudian manajer produksi akan menetapkan jumlah barang yang harus diproduksi esok hari.

2. Seorang pegawai melakukan kerjanya dengan kinerja yang sangat baik, kemudian atasan akan memberikan reward yang sesuai dengan kinerja pegawai tersebut.

Contoh pemetaan suatu input-output dalam bentuk grafis seperti terlihat pada gambar berikut :

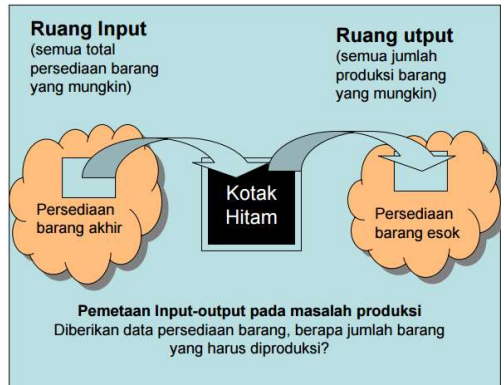

Gambar 2.2 Contoh Pemetaan Input-Output (Widodo, 2012)

\section{Fuzzy Inference System}

Sistem Inferensi Fuzzy(Fuzzy Inference System/FIS) disebut juga fuzzy inference engine adalah sistem yang dapat melakukan penalaran dengan prinsip serupa seperti manusia melakukan penalaran dengan nalurinya.

\section{Metode Tsukamoto}

Setiap konsekuen pada aturan yang berbentuk IF-THEN harus direpresentasikan dengan suatu himpunan fuzzy dengan fungsi keanggotaan yang monoton. Output hasil inferensi dari tiap-tiap aturan diberikan secara tegas (crisp) berdasarkan $\alpha$-predikat (fire strength). Hasil akhirnya diperoleh dengan menggunakan rata-rata terbobot.

\section{Metode Mamdani}

Metode Mamdani sering dikenal sebagai metode Max-Min, yang diperkenalkan oleh Ebrahim Mamdani tahun 1975. Untuk mendapatkan output diperlukan 4 tahapan (Sri Kusuma Dewi, 2013):

1. Pembentukan Himpunan Fuzzy

Pada metode mamdani, baik variabel input maupun variabel output dibagi menjadi satu atau lebih himpunan fuzzy.
2. Aplikasi Fungsi Implikasi

Pada metode mamdani, fungsi implikasi yang digunakan adalah Min.

3. Komposisi Aturan

Pada tahapan ini sistem terdiri dari beberapa aturan, maka inferensi diperoleh dari kumpulan dan korelasi antar aturan. Ada 3 metode yang digunakan dalam melakukan inferensi sistem fuzzy, yaitu : max, additive dan probabilistik OR. Pada metode max, solusi himpunan fuzzy diperoleh dengan cara mengambil nilai maksimum aturan, kemudian menggunakannya untuk memodifikasi daerah fuzzy, dan mengaplikasikanya ke output dengan menggunakan operator OR (union). Secara umum dapat ditulis :

$$
\mu \mathrm{sf}(\mathrm{xi})=\max (\mu \mathrm{sf}(\mathrm{xi}), \mu \mathrm{kf}(\mathrm{xi})) .
$$

\section{Penegasan (defuzzy)}

Input dari proses defuzzyfikasi adalah suatu himpunan fuzzy yang diperoleh dari komposisi aturan-aturan fuzzy, sedangkan output yang dihasilkan merupakan suatu bilangan pada domain himpunan fuzzy tersebut. Jika diberikan suatu himpunan fuzzy dalam range tertentu, maka harus dapat di ambil suatu nilai crisp tertentu sebagai output. Defuzzyfikasi pada metode mamdani untuk semesta diskrit menggunakan persamaan :

$$
\mathrm{z}=\sum \mathrm{zj} \mu(\mathrm{zj}) / \sum \mu(\mathrm{zj}) \text {. }
$$

\section{Metode Sugeno}

Penalaran SUGENO hampir sama dengan MAMDANI. Diperkenalkan oleh Takagi-Sugeno Kang tahun 1985. Output sistem tidak berupa himpunan fuzzy, melainkan berupa konstanta atau persamaan linier (Sri Kusuma Dewi, 2013).

\section{METODE PENELITIAN Analisa Kebutuhan}

Jenis Penelitian yang digunakan adalah model eksperimen. Penelitian ini menggunakan metode Fuzzy Inference System (FIS) untuk memudahkan pihak Carrefour dalam melakukan pembelian produk untuk persediaan sesuai dengan kebutuhan pasar. Jenis data yang digunakan dalam penelitian ini adalah data primer yang diperoleh peneliti secara langsung dari sumber dengan melakukan pengambilan data historis transaksi penjualan, data stok, dan data pembelian untuk setiap jenis produk.

\section{Metode Pengumpulan Data}


Metode yang digunakan peneliti dalam merancang pemodelan untuk menentukan jumlah pembelian produk adalah:

1. Sumber Data

a. Data Primer

Adalah data yang diperoleh secara langsung dari sumber, misalnya datadata hasil wawancara dengan kepala gudang dan bagian accounting di Carrefour Puri Indah dan data penjualan selama 1 tahun (2014-2015).

b. Data Sekunder

Adalah data yang diperoleh secara tidak langsung, misalnya dari literatur, buku, jurnal dan informasi lainya yang berhubungan dengan masalah persediaan.

2. Sampel Data Penelitian

Sampel data dari penelitian ini adalah data historis transaksi penjualan, data stok, dan data pembelian untuk setiap jenis produk dalam jangka waktu 1 tahun. Pada Carrefour Puri Indah jumlah jenis produk yang dijual adalah 29.976 jenis. Untuk pembelian produk, pihak Carrefour menerapkan sistem konsinyasi dan beli putus (tergantung kesepakatan dengan para pemasok). Untuk produk yang memiliki harga tinggi (seperti Elektronik, funiture, dll) pihak Carrefour menerapkan sistem konsinyasi. Berdasarkan data yang diperoleh bahwa terdapat 2000 jenis produk yang sifatnya beli putus artinya pihak Carrefour langsung membeli produk dari para pemasok, dimana pembayaran dilakukan setelah produk dikirim. Dan segala kerusakan akibat kadaluarsa dan biaya penyimpanan ditanggung oleh pihak Carrefour. Sedangkan selebihnya bersifat konsinyasi. Pada penelitian ini data yang diambil adalah data produk yang bersifat beli putus. Pengambilan sampel dapat dihitung dengan rumus:

$$
n=\frac{N}{N(d)^{2}+1}
$$

Keterangan:

$$
\begin{aligned}
& \mathrm{n}=\text { Sampel } \\
& \mathrm{N}=\text { Populasi } \\
& \mathrm{d}=\text { Nilai presisi misalnya } 95 \% \text { atau sig. } \\
& =0.05
\end{aligned}
$$

Oleh karena data yang digunakan adalah 2000 jenis barang dengan tingkat deteksi error adalah 5\%, maka sampel yang diambil sebanyak:

$$
\begin{gathered}
n=\frac{2000}{2000(0.05)^{2}+1} \\
=333,33=>334 \text { jenis data. }
\end{gathered}
$$

Data yang diperoleh dibagi dalam tiga kategori berdasarkan analisa historis transaksi penjualan yaitu: Fast Moving, Medium Moving dan Slow Moving. Pada penelitian ini, sampel data diambil secara random berdasarkan jenis produk dari berbagai merek. Sampel dari populasi data produk ditampilkan pada tabel di bawah ini:

Tabel 3.1 Sampel Data Produk

\begin{tabular}{|l|c|c|c|}
\hline \multirow{2}{*}{$\begin{array}{c}\text { Tahun } \\
\text { 2014/2015 }\end{array}$} & \multicolumn{3}{|c|}{ MINUMAN } \\
\cline { 2 - 4 } & Persediaan & Pembelian & Penjualan \\
\hline September & 46 & 100 & 73 \\
\hline Oktober & 73 & 50 & 73 \\
\hline November & 86 & 50 & 40 \\
\hline Desember & 96 & 100 & 120 \\
\hline Januari & 176 & 150 & 209 \\
\hline Februari & 117 & 0 & 57 \\
\hline Maret & 60 & 0 & 40 \\
\hline April & 20 & 75 & 78 \\
\hline Mei & 17 & 50 & 54 \\
\hline Juni & 13 & 100 & 81 \\
\hline Juli & 32 & 100 & 98 \\
\hline Agustus & 34 & 50 & 69 \\
\hline September & 15 & & \\
\hline
\end{tabular}

Penerapan Fuzzy Inference System Dalam Pembelian Produk Untuk Persediaan

Penerapan fuzzy inference system pada pengolahan data pembelian produk untuk persediaan menggunakan fuzzy logic model yang digunakan adalah model Mamdani, dengan tahapan sebagai berikut:

\section{Proses Fuzzification}

Pada penelitian ini akan diambil beberapa variabel yang dianggap penting dalam pembelian produk untuk persediaan, dan bisa di masukan kedalam bilangan Fuzzy sebagai sampel pengujian. Ada 10 sampel data yang digunakan seperti yang tertera pada Tabel 3.1.

Terdapat 2 variabel fuzzy sebagai input yang akan digunakan, yaitu:

1. Persediaan: terdiri dari 3 himpunan fuzzy, yaitu: SEDIKIT, SEDANG, dan BANYAK. 
2. Penjualan: terdiri dari 3 himpunan fuzzy, yaitu: SEDIKIT, SEDANG, dan BANYAK.

Terdapat 1 variabel fuzzy sebagai output yang akan digunakan, yaitu:

Jumlah Pembelian: terdiri dari 3 himpunan fuzzy, yaitu: SEDIKIT, SEDANG, dan BANYAK. X 4"

Data Pertama "COCA COLA CAN 330 ML

\section{a. Variabel Persediaan}

Tabel 3.2 Nilai Linguistik Persediaan data pertama

\begin{tabular}{|c|c|}
\hline Nilai Linguistik & Interval \\
\hline Sedikit & {$[1378,2]$} \\
\hline Sedang & {$[29,3159,7]$} \\
\hline Banyak & {$[110,8176]$} \\
\hline
\end{tabular}

$$
\mu \operatorname{Sedikit}(x)=\left\{\begin{array}{ll}
\frac{78,2-x}{78,2} & 13 \leq x \leq 78,2 \\
0 ; & x \geq 78,2
\end{array}\right\}
$$

$$
\mu \operatorname{Sedang}(x)
$$$$
=\left\{\begin{array}{cc}
0 ; & x \leq 29,3 \text { atau } x \geq 159,7 \\
\frac{x-29,3}{78,2} & 29,3 \leq x \leq 94,5 \\
\frac{159,7-x}{78,2} & 94,5 \leq x \leq 159,7
\end{array}\right\}
$$

$$
\mu \operatorname{Banyak}(x)
$$

$$
=\left\{\begin{array}{cc}
0 ; & x \leq 110,8 \\
\frac{x-110,8}{78,2} & 110,8 \leq x \leq 176 \\
1 ; & x \geq 176
\end{array}\right\}
$$

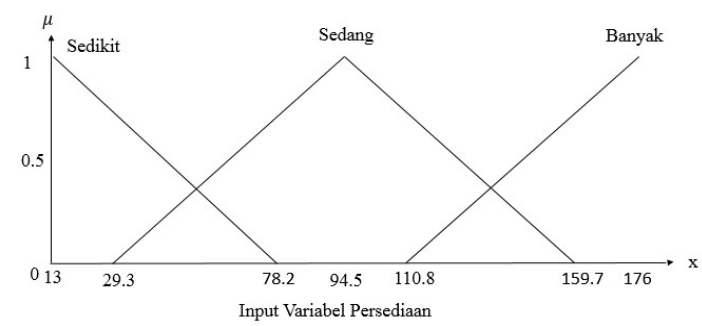

Gambar 3.3 Input Variabel Persediaan data pertama

\section{b. Variabel Penjualan}

Tabel 3.3 Nilai Linguistik Penjualan data pertama

\begin{tabular}{|c|c|}
\hline Nilai Linguistik & Interval \\
\hline Sedikit & {$[40107,6]$} \\
\hline Sedang & {$[56,9192,1]$} \\
\hline Banyak & {$[141,4209]$} \\
\hline
\end{tabular}

$\mu$ Sedikit $(y)=\left\{\begin{array}{ll}\frac{107,6-y}{107,6} & 40 \leq y \leq 107,6 \\ 0 ; & y \geq 107,6\end{array}\right\}$

$\mu \operatorname{Sedang}(y)$

$=\left\{\begin{array}{ll}0 ; & y \leq 56,9 \text { atau } y \geq 192,1 \\ \frac{y-56,9}{107,6} & 56,9 \leq y \leq 124,5 \\ \frac{192,1-y}{107,6} & 124,5 \leq y \leq 192,1\end{array}\right\}$

$\mu \operatorname{Banyak}(y)$

$=\left\{\begin{array}{cc}0 ; & y \leq 141,4 \\ \frac{y-141,4}{107,6} & 141,4 \leq y \leq 209 \\ 1 ; & y \geq 209\end{array}\right\}$

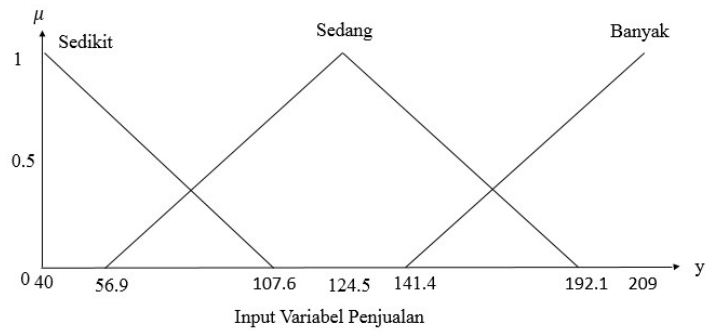

Gambar 3.4 Input Variabel Penjualan data pertama

\section{c. Variabel Pembelian}

Tabel 3.4 Nilai Linguistik Pembelian data pertama

\begin{tabular}{|c|c|}
\hline $\begin{array}{c}\text { Nilai } \\
\text { Linguistik }\end{array}$ & Interval \\
\hline Sedikit & {$[060]$} \\
\hline Sedang & {$\left[\begin{array}{lll}15 & 135\end{array}\right]$} \\
\hline Banyak & {$\left[\begin{array}{ll}90 & 150\end{array}\right]$} \\
\hline
\end{tabular}

$\mu \operatorname{Sedikit}(z)=\left\{\begin{array}{ll}\frac{60-z}{60} & 0 \leq z \leq 60 \\ 0 ; & z \geq 60\end{array}\right\}$

$\mu \operatorname{Sedang}(z)$

$=\left\{\begin{array}{lc}0 ; & z \leq 15 \text { atau } z \geq 135 \\ \frac{z-15}{60} & 15 \leq z \leq 75 \\ \frac{135-z}{60} & 75 \leq z \leq 135\end{array}\right\}$

$\operatorname{\mu Banyak}(z)=\left\{\begin{array}{ll}0 ; & z \leq 90 \\ \frac{z-90}{60} & 90 \leq z \leq 150 \\ 1 ; & z \geq 150\end{array}\right\}$ 


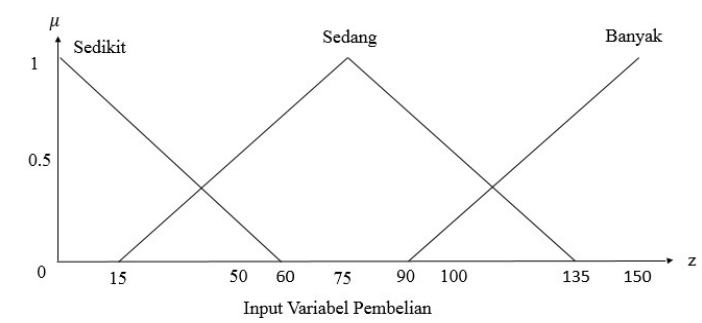

Gambar 3.5 Input Variabel Pembelian data pertama

\section{Proses Fuzzy Inference System}

Tabel 3.5 Aturan Fuzzy dalam pembelian produk untuk persediaan

\begin{tabular}{|c|l|l|l|}
\hline \multirow{2}{*}{ Aturan } & \multicolumn{2}{|c|}{ INPUT } & OUTPUT \\
\cline { 2 - 4 } & Persediaan & Penjualan & Pembelian \\
\hline 1 & Sedikit & Sedikit & Sedikit \\
\hline 2 & Sedikit & Sedang & Sedang \\
\hline 3 & Sedikit & Banyak & Banyak \\
\hline 4 & Sedang & Sedikit & Sedikit \\
\hline 5 & Sedang & Sedang & Sedang \\
\hline 6 & Sedang & Banyak & Banyak \\
\hline 7 & Banyak & Sedikit & Sedikit \\
\hline 8 & Banyak & Sedang & Sedang \\
\hline 9 & Banyak & Banyak & Banyak \\
\hline
\end{tabular}

Setelah penentuan fungsi keanggotaan variabel, maka dilakukan pembentukan aturan logika fuzzy. Berdasarkan data - data yang ada, dapat dibentuk aturan - aturan sebagai berikut:

1. if (Persediaan is Sedikit) and (Penjualan is Sedikit) then (Pembelian is Sedikit)

2. if (Persediaan is Sedikit) and (Penjualan is Sedang) then (Pembelian is Sedang)

3. if (Persediaan is Sedikit) and (Penjualan is Banyak) then (Pembelian is Banyak)

4. if (Persediaan is Sedang) and (Penjualan is Sedikit) then (Pembelian is Sedikit)

5. if (Persediaan is Sedang) and (Penjualan is Sedang) then (Pembelian is Sedang)

6. if (Persediaan is Sedang) and (Penjualan is Banyak) then (Pembelian is Banyak)

7. if (Persediaan is Banyak) and (Penjualan is Sedikit) then (Pembelian is Sedikit)

8. if (Persediaan is Banyak) and (Penjualan is Sedang) then (Pembelian is Sedang)

9. if (Persediaan is Banyak) and (Penjualan is Banyak) then (Pembelian is Banyak).

\section{Proses Defuzzification}

Langkah terakhir adalah penegasan (defuzzyfikasi). Pada data pertama kategori minuman dengan jenis produk Coca Cola Can 330 ML x 4 untuk menentukan jumlah pembelian pada bulan september 2015, maka dibutuhkan data persediaan dan penjualan pada bulan-bulan sebelumnya (selama satu tahun). Misalkan data yang digunakan adalah persediaan akhir bulan agustus 2015 (awal september) dan penjualan bulan agustus 2015. Data persediaan untuk bulan agustus 2015 (awal september) adalah sebesar 15 unit. Sedangkan untuk data penjualan pada bulan agustus 2015 adalah sebesar 69 unit, maka jumlah pembelian untuk bulan september adalah sebagai berikut:

1. Jumlah Persediaan

Jumlah persediaan 15 unit terdapat pada himpunan Sedikit, maka:

$$
\begin{aligned}
& \mu \text { Sedikit }(x) \\
& =\left\{\begin{array}{cc}
\frac{78,2-x}{78,2} & 13 \leq x \leq 78,2 \\
0 ; & x \geq 78,2
\end{array}\right\} \\
& \mu \operatorname{Sedikit}(x)=\frac{78,2-15}{78,2}=0.81
\end{aligned}
$$

2. Jumlah Penjualan

Jumlah penjualan 69 unit terdapat pada himpunan Sedikit dan Sedang, maka:

$$
\begin{aligned}
& \mu \text { Sedikit }(y) \\
& =\left\{\begin{array}{cc}
\frac{107,6-y}{107,6} & 40 \leq y \leq 107,6 \\
0 ; & y \geq 107,6
\end{array}\right\} \\
& \mu \operatorname{Sedikit}(y)=\frac{107,6-69}{107,6}=0.36
\end{aligned}
$$

$$
\begin{gathered}
\mu \text { Sedang }(y) \\
=\left\{\begin{array}{ll}
0 ; & y \leq 56,9 \text { atau } y \geq 192,1 \\
\frac{y-56,9}{107,6} & 56,9 \leq y \leq 124,5 \\
\frac{192,1-y}{107,6} & 3500 \leq y \leq 192,1
\end{array}\right\} \\
\mu \operatorname{Sedang}(y)=\frac{69-56,9}{107,6}=0.11
\end{gathered}
$$

Dengan menggunakan inference clipping didapat nilai sebagai berikut:

1. Jika Persediaan Sedikit( 0.81$)$ and Penjualan Sedikit(0.36) then Pembelian Sedikit(0.36), 
2. Jika Persediaan Sedikit(0.81) and Penjualan Sedang $(0.11)$ then Pembelian Sedang(0.11).

Dengan metode centroid method/center of grafity sebagai berikut:

$$
\begin{gathered}
z^{*}=\frac{\int_{Z} z \mu(z) d z}{\int_{Z} \mu(z) d z} \\
\text { Atau } \\
z^{*}=\frac{\sum_{j=1}^{n} z_{j} \mu\left(z_{j}\right)}{\sum_{j=1}^{n} \mu\left(z_{j}\right)}
\end{gathered}
$$

Output Pembelian produk:

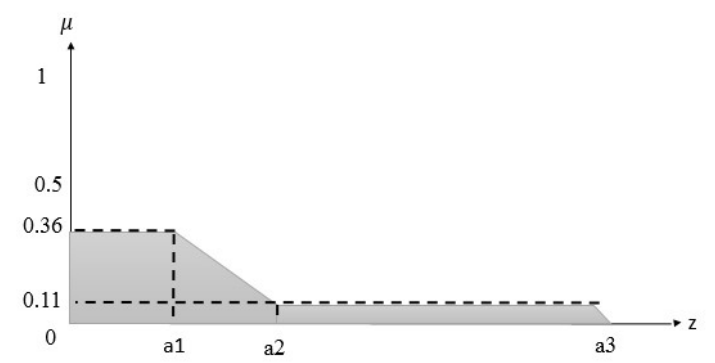

Gambar 3.6 Daerah Hasil Komposisi Pembelian Produk

Mencari Nilai a1, a2, a3, dan a4 :

$$
\begin{aligned}
& \mathrm{a} 1=>\frac{60-z}{60}=0.36=38,4 \\
& \mathrm{a} 2=>\frac{60-z}{120}=0.11=53,4 \\
& \text { a3 }=>\frac{135-z}{60}=0.00=135
\end{aligned}
$$

Menghitung Momen untuk setiap daerah :

$$
\begin{gathered}
M 1=\int_{0}^{38,45} 0.36 z d z=0,\left.18 z^{2}\right|_{0} ^{38,4}=265,42 \\
M 2=\int_{38,4}^{53,4} \frac{60-z}{60} z d z=\int_{38,4}^{53,4} z-0,017 z^{2} d z \\
=0.5 z^{3}-\left.0.057 z^{2}\right|_{38,4} ^{53,4} \\
=143,29
\end{gathered}
$$

$M 3=\int_{53,4}^{135} 0.11 z d z=0,\left.055 z^{2}\right|_{53,4} ^{135}=845,54$

Menghitung Luas setiap daerah:

$$
A 1=38,4 \times 0.36=13,83
$$

$$
\begin{gathered}
A 2=(0.36+0.11) \times(53,4-38,4) / 2 \\
=3,53 \\
A 1=(135-53,4) \times 0.11=8,98
\end{gathered}
$$

Titik pusat dapat diperoleh dari:

$$
\begin{gathered}
\frac{265,42+143,29+845,54}{13,83+3,53+8,98}=\frac{1254,25}{26,34} \\
=47,6
\end{gathered}
$$

Kesimpulan, Jika Persediaan 15 unit dan Penjualan 69 unit maka Jumlah Pembelian Produk adalah 48 unit.

\section{HASIL DAN PEMBAHASAN}

Hasil Penerapan Logika Fuzzy (Mamadani) Untuk Menentukan Jumlah Pembelian Produk Untuk Persediaan

1. Tampilan Fuzzy Inference System a. Tampilan Input Variabel Persediaan

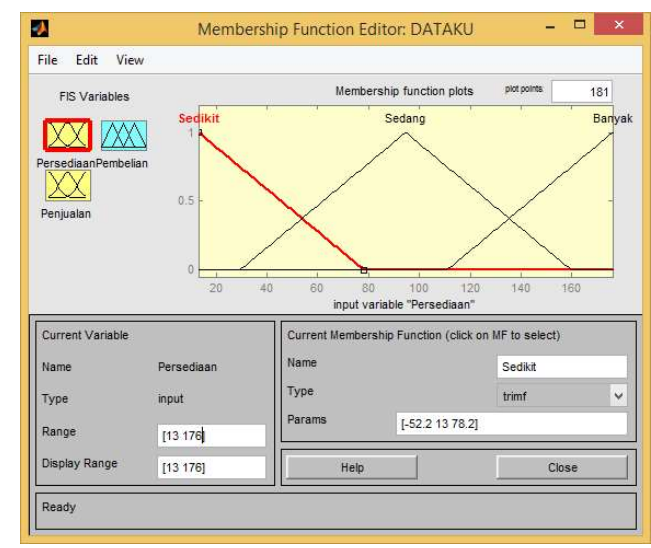

Gambar 4.7 Tampilan Input Variabel Persediaan

b. Tampilan Input Variabel Penjualan

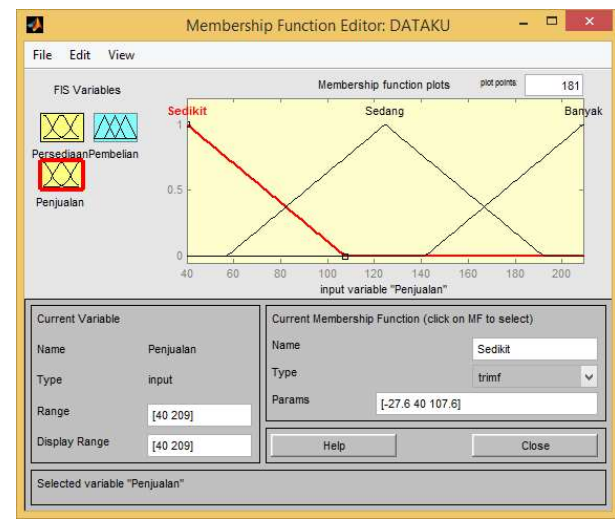

Gambar 4.8 Tampilan Input Variabel Penjualan 
c. Tampilan Input Variabel Pembelian

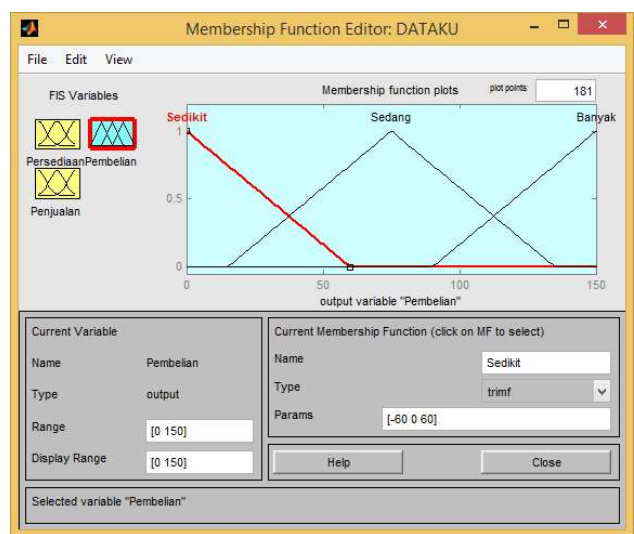

Gambar 4.9 Tampilan Input Variabel Pembelian

2. Tampilan Aturan (Rule)

Pada tampilan rule digunakan untuk memasukkan aturan-aturan yang telah ditentukan berdasarkan input-an variabel

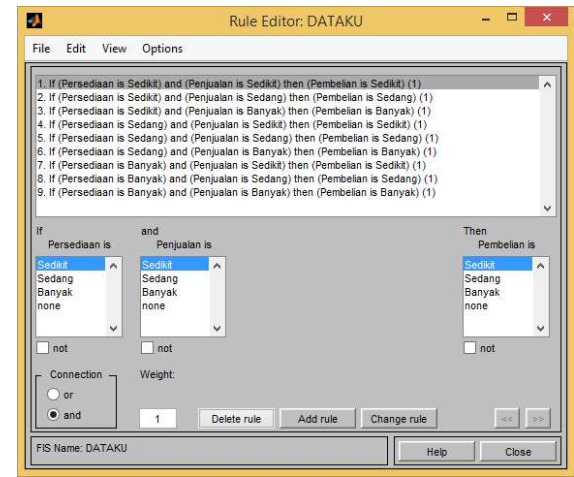

Gambar 4.10 Tampilan Aturan (rule)

3. Tampilan Komposisi Atuaran (Rule)

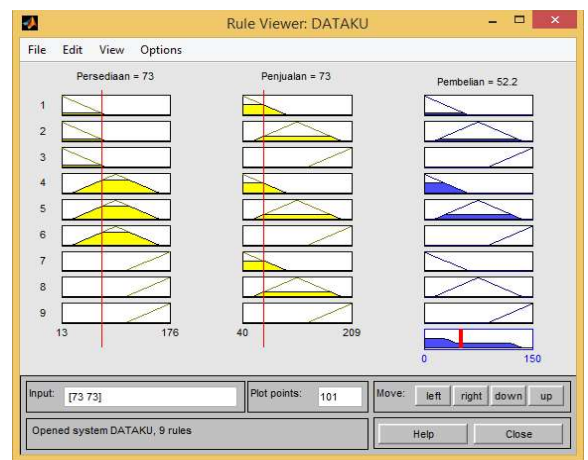

Gambar 4.11 Tampilan Komposisi Aturan (rule)

4. Tampilan Diagram Metode Mamdani

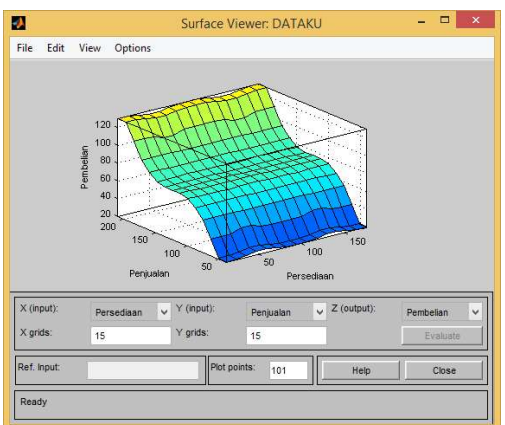

Gambar 4.12 Tampilan Diagram Metode Mamdani

\section{Data Training}

\section{DATA TRAINING}

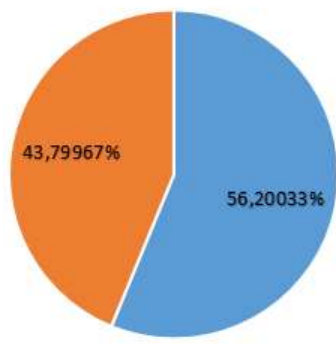

$\because$ KESALAHAN $\because$ KEBENARAN

Bagan 4.1 Tingkat Kesalahan dan Kebenaran pada Data Training

\section{Data Testing}

DATA TESTING

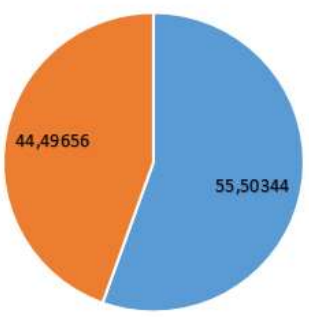

$\varpi$ KESALAHAN $\cong$ KEBENARAN

Bagan 4.2 Tingkat Kesalahan dan Kebenaran pada Data Testing

\section{PEMBAHASAN}

Dari hasil perhitungan yang telah dilakukan dengan metode fuzzy inference system dijelaskan bahwa data training dan data testing sangat akurat dengan selisih $0,69689 \%$.

\section{KESIMPULAN}

Berdasarkan rumusan masalah, hasil penelitian dan pembahasan mengenai 
penentuan jumlah pembelian produk berdasarkan data persediaan dan penjualan dapat diambil beberapa kesimpulan, yaitu:

1. Logika fuzzy (Mamdani) dalam menentukan jumlah pembelian produk untuk persediaan yang telah dibangun dapat digunakan untuk membantu perusahaan dalam mengambil sebuah keputusan dengan nilai kebenaran mencapai 44,49656\% untuk data testing.

2. Logika fuzzy (mamdani) yang telah dibangun dapat membantu pihak Carrefour dalam menentukan jumlah pembelian produk untuk persediaan pada bulan berikutnya.

\section{DAFTAR PUSTAKA}

[1] Darmanto, E. (2012). Modified ABC Analysis Untuk klasifikasi Inventori. Sistem Pendukung Keputusan, Komputasi dan Simulasi (hal. 70). Yogyakarta: Graha Ilmu.

[2] Dewanti, T. (2010). Manajemen Persediaan pada Perusahaan Baja Ringan di Yogyakarta. Jurnal Ilmiah.

[3] Ekong. (2013). A fuzzy inference system for predicting depression risk levels. African Journal of Mathematics and Computer Science Research .

[4] Ferry. (2011). Penerapan Fuzzy C-Means Dan Apriori Untuk Rekomendasi Promosi Produk Berdasarkan Segmentasi Konsumen.

[5] Kaur, A. (2012). Comparison of Mamdani-Type and Sugeno-Type Fuzzy Inference Systems for Air Conditioning System . International Journal of Soft Computing and Engineering (IJSCE) .

[6] Muzayyanah, I. (2014). Sistem Pendukung Keputusan Untuk Penentuan Persediaan Bahan Baku Dan Membantu Target Marketing Industri Dengan Metode Fuzzy Inference System Tsukamoto. Jurnal Ilmiah.

[7] Nugraheni, Y. (2011). Data Mining Dengan Metode Fuzzy Untuk Customer Relationship Management (Crm) Pada Perusahaan Retail.

[8] Nurina, A. F. (2010). Estimasi Penjualan Suku Cadang Mobil Menggunakan Fuzzy Sugeno. Makalah Proyek Akhir.

[9] Nurul, E. (2010). Implementasi Klasifikasi Item Persediaan Pada Rumah Sakit Menggunakan Metode Abc-Fuzzy Classification.

[10] Puspitasari, D. (2008). Penjualan. Jakarta: Direktorat Pembinaan Sekolah Menengah Kejuruan .

[11] Rezaei, H. R. (2012). Developing an Intelligent Inventory Control Model, Applying Fuzzy Logic and Association Rule Mining . International Journal of Emerging Technology and Advanced Engineering .
[12] Sri Kusuma Dewi, H. P. (2013). Aplikasi Logika Fuzzy Untuk Pendukung Keputusan. Yogyakarta: Graha Ilmu.

[13] Sunyoto, D. (2015). Manajemen Bisnis Ritel. Jakarta: CAPS (Center for Academic Publishing Service).

[14] Tanthatemee. (2012). Fuzzy Inventory Control System for Uncertain Demand and Supply .

[15] Ula, M. (2014). Implementasi Logika Fuzzy Dalam Optimasi Jumlah Pengadaan Barang Menggunakan Metode Tsukamoto. Jurnal ECOTIPE.

[16] Widodo, P. P. (2012). Penerapan Soft Computing dengan Matlab. Bandung: Rekayasa Sains.

[17] Yazid, E. (2009). Penerapan Kendali Cerdas Pada Sistem Tangki Air Menggunakan Logika Fuzzy. Jurnal Fisika Himpunan Fisika Indonesia. 